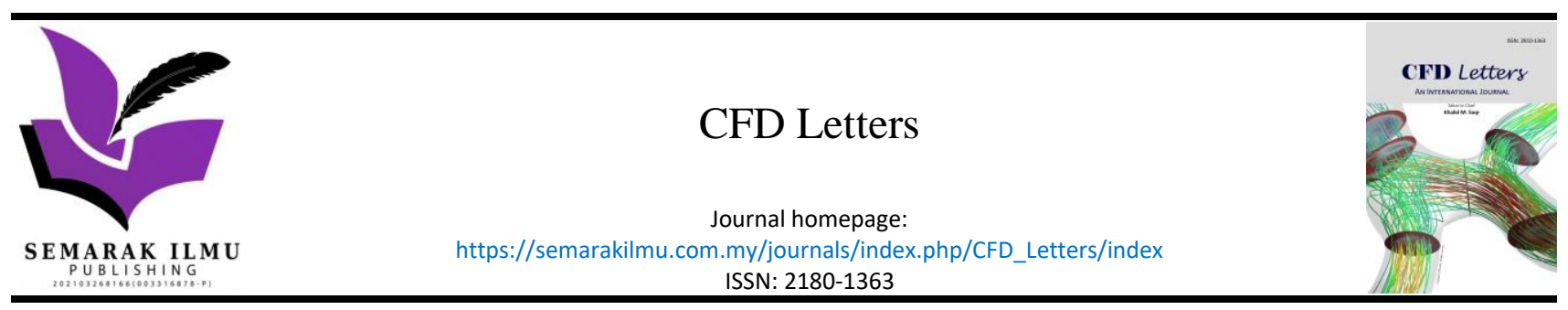

\title{
Thermal Resistance and Pressure Drop Minimization for a Micro-gap Heat Sink with Internal Micro-fins by Parametric Optimization of Operating Conditions
}

\author{
Shugata Ahmed ${ }^{1}$, Erwin Sulaeman ${ }^{2,}{ }^{*}$, Ahmad Faris Ismail ${ }^{2}$, Muhammad Hasibul Hasan $^{3}$, Zahir \\ Hanouf $^{4}$ \\ Department of Robotics and Mechatronics Engineering, Faculty of Engineering and Technology, University of Dhaka, Dhaka 1000, Bangladesh \\ Department of Mechanical Engineering, Faculty of Engineering, International Islamic University Malaysia, Jalan Gombak, 53100 Kuala Lumpur, \\ Malaysia \\ 3 Departmental of Mechanical and Industrial Engineering, Faculty of Engineering and Architectural Science, Ryerson University, 350 Victoria \\ Street, Toronto, ON 5MB 2K3, Canada \\ 4 Department of Mechanical Engineering, Faculty of Engineering. University of Bahrain, Bahrain
}

ARTICLE INFO ABSTRACT

\section{Article history:}

Received 3 October 2021

Received in revised form 1 December 2021

Accepted 2 December 2021

Available online 15 December 2021

\section{Keywords:}

Thermal resistance; wall heat flux; pumping power; void fraction

\begin{abstract}
In recent years, researchers are investigating several potential applications of twophase flow in micro-gap heat sinks; electronic cooling is one of them. Further, internal micro-fins are used to enhance the heat transfer rate. However, the pressure drop penalty due to small gap height and fin surfaces is a major concern. Hence, minimization of thermal resistance and pressure drop is required. In this paper, effects of operating conditions, e.g., wall heat flux, pumping power, and inlet void fraction, on total thermal resistance and pressure drop in a micro-gap heat sink with internal micro-fins of rectangular and triangular profiles have been investigated by numerical analysis for the R-134a coolant. Furthermore, optimization of these parameters has been carried out by response surface methodology. Simulation results show that rectangular micro-fins show superior performance compared to triangular fins in reducing thermal resistance. Finally, for an optimum condition $\left(7.1202 \times 10^{-5} \mathrm{~W}\right.$ pumping power, $1.2 \times 107 \mathrm{Wm}^{-2}$ heat flux, and 0.03 inlet void fraction), thermal resistance and pressure drop are reduced by $56.3 \%$ and $87.2 \%$, respectively.
\end{abstract}

\section{Introduction}

Overheating is a major concern for high-performance electronic devices, such as supercomputers and data centers [1]. As traditional air-cooling is not sufficient for these devices, liquid coolants are used. Evaporation of the coolant in the heat sink escalates the heat transfer rate [2]. Again, a wide range of investigations has been carried out on the shape of the heat sink to increase heat flux. Researchers have found micro-channel heat sinks, introduced by Tuckerman and Peace [3], advantageous for their high heat transfer capability, although having high-pressure drop penalty. In recent years, micro-gap heat sinks are considered a potential candidate for electronic cooling

\footnotetext{
* Corresponding author.

E-mail address: esulaeman@iium.edu.my (Erwin Sulaeman)
}

https://doi.org/10.37934/cfdl.13.12.100112 
compared to micro-channels due to low-pressure drop [4,5]. A wide range of studies on heat transfer characteristics of mini and micro-channels have been found in the literature. Prediction of heat transfer coefficients associated with variable heat and mass fluxes in a stainless-steel mini channel tube of $2 \mathrm{~m}$ length and $3 \mathrm{~mm}$ diameter has been reported by Akbar et al., [6]. In previous publications, the authors of this paper proposed incorporating micro-fins in the micro-gap to enhance the cooling rate [7-12]. Few similar studies have been found in the literature as well [13-16]. However, optimization of operating conditions to minimize thermal resistance and pressure drop was missing in previous articles. A summary of other author's works on the optimization of heat sinks is presented below.

Khan et al., [17] utilized the Entropy Generation Minimization (EGM) technique to optimize the overall performance of microchannel heat sink (MCHS) contemplating Knudsen number, volumetric flow rate, aspect ratio, fin spacing ratio, the thermal conductivity of channel material, and accommodation coefficient as variables. Entropy generation rate was found inversely proportional to Knudsen number in slip flow region. Chen [18] presented an analysis for optimizing microchannel geometry by using Forchheimer-Brinkman-extended Darcy equation and two-equation model for heat transfer between the solid and fluid phases. Based on his works, it was found that fluid inertia force alters the dimensionless velocity and fluid temperature distribution, while solid temperature distribution is almost sensitive to the fluid inertia by varying channel aspect ratio, internal force parameters, porosity, and effective thermal conductivity ratio. Asgari and Saidi [19] presented an approximate method for determining the optimum cross-section of microchannel heat sink for laminar flow conditions. The solutions were presented for 10 different cross-sections such as parallel plate channel, circular duct, rectangular channel, elliptical channel, polygonal channel, etc. The model, validated using results from open literature, is only a function of the Prandtl number and geometrical parameters of the channel. Results demonstrated that dimensionless heat transfer from the triangular channel is higher than other cross-sectional shapes considered. Kim et al., [20] conducted thermal optimization of a plate-fin heat sink with the fin thickness variations in the direction normal to the fluid flow. The model is based on Volume Averaging Theory (VAT). It was shown that the thermal resistance of the plate heat sink can be reduced by allowing the fin thickness to increase in the direction normal to the fluid flow. In the case of a water-cooled heat sink, the thermal resistance is decreased by about $15 \%$. The amount of reduction increases with the increasing pumping power or decreasing length of the heat sink. Baodong et al., [21] presented a multi-objective optimization design of a MCHS using an adaptive genetic algorithm by taking thermal resistance and pressure drop as functions to be minimized. The procedure aims to find out the most favorable geometry of MCHS to minimize heat sink size and obtain minimum pressure drop simultaneously. The optimization results showed that the optimized width of channel and fin thickness is $197 \mu \mathrm{m}$ and $50 \mu \mathrm{m}$, respectively and total thermal resistance is $0.838 \mathrm{~K} / \mathrm{W}$ for constant pumping power (8W). The results reveal that the optimized micro-channel heat sink can improve cooling performance significantly. Hung et al., [22] proposed an optimization method that combines the Simple Conjugate Gradient Method (SCGM) and a three-dimensional model to optimize thermal resistance for doublelayer microchannel heat sink (DL-MCHS) by monitoring the effect of the number of channels, channel width ratio, and upper and lower channel aspect ratios. The design is only suitable for low pumping power due to the thermal resistance, which tends to approach a constant value as pumping power increases. Adham et al., [23] investigated the overall performance of forced convection ammonia cooled rectangular microchannel heat sink using a multi-objective Non-dominated Sorting Genetic Algorithm (NSGA). Optimum channel aspect ratio and channel wall-to-width ratio were determined by NSGA. From the investigation, using ammonia cooled microchannel heat sink, a total thermal 
resistance reduction of up to $34 \%$ was observed compared to an air-cooled microchannel heat sink under the same operating conditions.

From the state of the art presented above, it is realized that optimization of operating conditions for micro-gap heat sinks with internal micro-fins is absent in the literature. This paper presents a numerical work to investigate the effects of operating conditions, e.g., wall heat flux, pumping power, and inlet void fraction, on total thermal resistance and pumping power using R-134a as a coolant. The objective is to minimize these two functions by optimizing the operating conditions. For optimized inputs, a significant reduction in pressure drops and total thermal resistance has been observed.

\section{Methodology}

Firstly, total thermal resistance and pressure drop have been investigated numerically as a function of operating conditions. After that response surfaces are plotted, and contour plots are obtained by Design Expert software. Finally, from given optimized values by the software, the proposed values are chosen for minimum pressure drop while total thermal resistance drops sufficiently as well.

\subsection{Multiphase Flow and Turbulence Modelling}

The Volume of Fluid (VOF) method [24] has been used to model the multiphase flow. The void fraction equation is the following

$\frac{\partial\left(\alpha \rho_{v}\right)}{\partial t}+\nabla \cdot\left(\alpha \rho_{v} \vec{v}_{v}\right)=m_{e v p}$

Here $\alpha$ is the void fraction, $\rho_{v}$ is the vapor density, $\vec{v}_{v}$ is the vapor velocity vector and $m_{\text {evp }}$ is rate of mass transfer from liquid to vapor phase due to evaporation. The void fraction is defined mathematically as follows

$\alpha=\frac{1}{V} \int_{V} I(\chi, t) d V$

Here $I(\chi, t)$ is known as the marker function, which is a multi-dimensional unit step function. In the primary phase, the value of the marker function is 1 , while in the secondary phase it is 0 .

The conservation of momentum equation

$\frac{\partial(\rho \vec{v})}{\partial t}+\nabla \cdot(\alpha \rho \vec{v} \vec{v})=-\nabla P+\nabla \tau+\rho \vec{g}+\vec{F}$

Here $\tau$ is wall shear stress and $g$ is gravitational acceleration. For Newtonian fluid, the shear stress is expressed as follows

$\tau=\mu[\nabla v+(\nabla v) T]$

Here $\mu$ is the dynamic viscosity. The conservation of energy equation for the fluid domain 
$\frac{\partial(\rho E)}{\partial t}+\nabla \cdot(\vec{v}(\rho E+P))=\nabla\left(k_{e f f} \nabla T\right)$

Here $k_{\text {eff }}$ is the effective thermal conductivity. Again, for the solid domain

$\nabla .\left(k_{S} \nabla T_{s}\right)=\frac{\partial\left(\rho_{s} c_{p, s} T_{s}\right)}{\partial t}$

Here $c_{p, s}$ is specific heat capacity of solid at constant pressure.

Internal fins are responsible for turbulence generation [10]. Hence, it is important to model turbulence in the flow field. The following equation is used to calculate the turbulence kinetic energy [25]

$\frac{\partial k}{\partial t}+\nabla(\vec{v} \cdot k)=\frac{1}{\rho}\left[\nabla\left(a_{k} \cdot \mu_{e f f} \cdot \nabla k\right)+G_{k}+G_{b}-\rho \varepsilon-Y_{M}+S_{k}\right]$

Here, $G_{k}=$ generation of turbulent kinetic energy due to the mean velocity gradients. $G_{b}=$ generation of turbulent kinetic energy due to buoyancy. $Y_{M}=$ contribution of the fluctuating dilatation in compressible turbulence to the overall dissipation rate. $\varepsilon=$ turbulence energy dissipation rate. Again, the equation based on turbulence kinetic energy dissipation rate [25]

$\frac{\partial \varepsilon}{\partial t}+\nabla(\vec{v} \cdot \varepsilon)=\frac{1}{\rho}\left[\nabla\left(a_{\varepsilon} \cdot \mu_{e f f} \cdot \nabla \varepsilon\right)+C_{1 \varepsilon} \frac{\varepsilon}{k}\left(G_{k}+C_{3 \varepsilon} G_{b}\right)-C_{2 \varepsilon} \rho \frac{\varepsilon^{2}}{k}-R_{\varepsilon}+S_{\varepsilon}\right]$

$\alpha_{k}$ and $\alpha_{\varepsilon}$ are inverse effective Prandtl numbers for $k$ and $\varepsilon$, respectively and $S_{k}$ and $S_{\varepsilon}$ are source terms. The model constants have the following default values

$C_{1 \varepsilon}=1.42, C_{2 \varepsilon}=1.68$

\subsection{Modelling Mass Transfer}

During boiling, mass is transferred from liquid to vapor phase. Modelling mass transfer rate due to evaporation includes determining empirical model for calculating evaporation rate and define the constraint to maintain interfacial temperature condition.

\subsection{Initial and Boundary Conditions}

At time $t=0 ; v=0, T_{f}=T_{s}=T_{a t m}, \alpha=0$. Various boundary conditions are defined at the inlet, outlet, and outer walls of the heat sinks. At the inlet: $T_{f}=T_{i n}, v=v_{i n}, \alpha=\alpha_{i n}$. Turbulence intensity is also defined at the inlet. For fully developed internal flow, turbulence intensity is calculated from the following formula

$I=\frac{u^{\prime}}{u_{\text {avg }}}=0.16(R e)^{-\frac{1}{8}}$

Again, atmospheric pressure is defined at the outlet: $P=P_{\text {out }}=P_{\text {atm }}$. Heat transfer from wall to fluid is by convection. Convective heat transfer coefficient is calculated from the following equation 
$h=\frac{Q_{e f f}}{A_{f}\left(T_{s}-T\right)}$

Uniform heat flux is applied at the bottom of the heat sink. Heat is transferred through the solid wall by conduction in the normal direction of the bottom surface. Heat flux transferred by conduction is calculated from the following equation

$$
q=-k_{s} \frac{\partial T_{s}}{\partial n}
$$

Adiabatic condition is applied to other channel walls. Hence, $q_{\text {loss }}=0$. As a result, temperature gradient at boundaries

$$
\frac{\partial T_{s}}{\partial n}=0
$$

\subsection{Heat-sink Dimensions and Range of Operating Conditions}

Dimensions of the micro-gap heat sink are shown in Table 1 and the range of operating conditions are given in Table 2. Noted that R-134a is used as coolant. A detail numerical study of R-134a is reported by Touaibi and Koten [26].

\section{Table 1}

Dimensions of micro-gap heat sinks

\begin{tabular}{lll}
\hline Parameters (unit) & Rectangular fin gap & Triangular fin gap \\
\hline Cross-sectional area, $A_{c s}\left(\mathrm{~mm}^{2}\right)$ & 21.8 & 21.8 \\
Convective surface area, $A_{f}\left(\mathrm{~mm}^{2}\right)$ & $2.66 \times 10^{-3}$ & $2.04 \times 10^{-3}$ \\
Hydraulic diameter, $D_{h}(\mathrm{~mm})$ & 1.11 & 1.45 \\
\hline
\end{tabular}

Table 2

Range of operating conditions

\begin{tabular}{ll}
\hline Operating conditions (unit) & Range \\
\hline Wall heat flux, $q_{\text {in }}\left(\mathrm{Wm}^{-2}\right)$ & $1 \times 10^{6}-8 \times 10^{6}$ \\
Pumping power, $\Omega(W)$ & $0.8 \times 10^{-4}-1 \times 10^{-3}$ \\
Inlet void fraction, $\alpha$ & $0-0.8$ \\
\hline
\end{tabular}

\subsection{Validation of Numerical Model}

The numerical model has been validated experimentally. The experimental setup has been presented in another publication of the author [11]. Validation results are given in Figure 1 and Figure 2. Figure 1 shows that Biot number decreases with the increment of Reynolds number calculated from outlet vapour velocity. Pressure drop also decreases with the decrement of vapour Reynolds number (Figure 2). Note that in the figures, dimensionless heat flux is constant, which is the ratio of heat flux absorbed by the fluid to heat flux supplied at the bottom of the heat sink. Mathematically, $\bar{q}=\frac{q_{\text {eff }}}{q_{\text {in }}}$. 


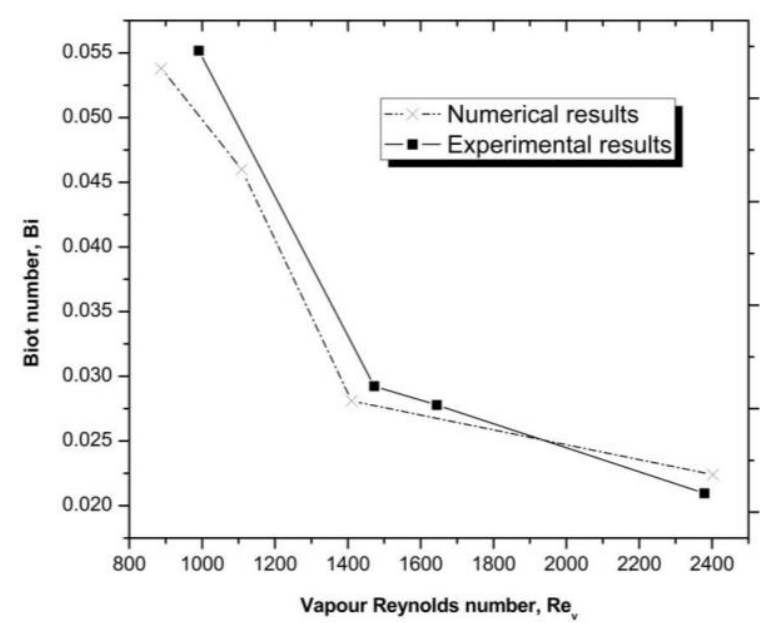

Fig. 1. Plot of Biot number against vapour Reynolds number for numerical and experimental results when $\bar{q}=1$

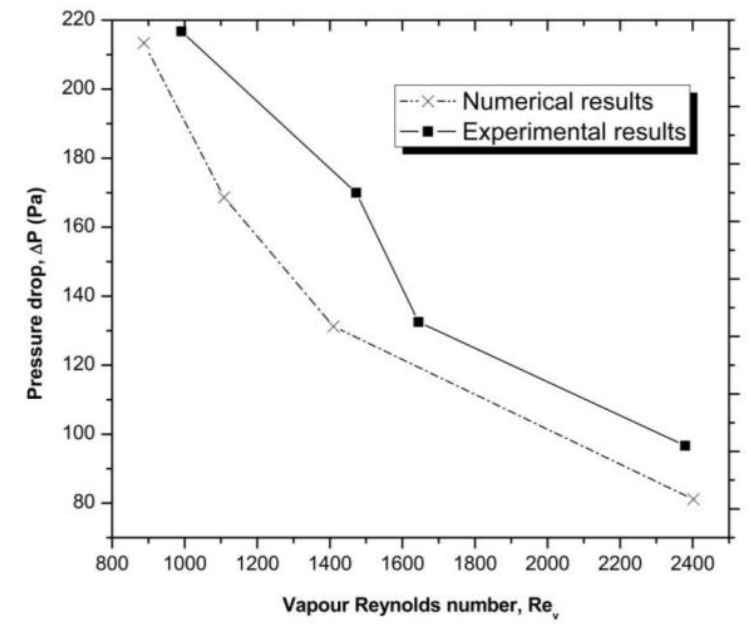

Fig. 2. Pressure drop vs. vapour Reynolds number plot for numerical and experimental results when $\bar{q}=1$

\subsection{Optimization Using RSM}

Response surface methodology (RSM) is a well-recognized, widely used technique for optimization. RSM explores agreement between desired outcomes and controllable input parameters by regression analysis. RSM provides optimum values of design parameters from a statistical model.

\section{Results and Discussion}

\subsection{Effect of Operating Conditions}

The considered operating conditions are wall heat flux, pumping power, and inlet void fraction. The effect of these parameters on evaporation rate, thermal resistance, pressure drop, wall shear stress, and generation of turbulence kinetic energy are discussed.

\subsubsection{Thermal resistance}

From Figure 3, it is perceived that the convective heat transfer coefficient $(h)$ of rectangular fin micro-gap is higher than that of triangular fin gap. From Eq. (10), it is observed that $h$ depends on fin surface area $\left(A_{f}\right)$. Rectangular fins have a larger surface area than triangular fins. Hence, the convective heat transfer coefficient is greater for the rectangular fin micro-gap heat sink. Because of the higher heat transfer coefficient, the total thermal resistance $\left(R_{t h}\right)$ of the rectangular fin micro-gap is lower than that of the triangular fin heat sink. Gunnasegaran et al., [27] also noticed that triangular microchannel heat sinks exhibit lower thermal performance than rectangular microchannels.

Again, from Figure 3. it is seen that the two-phase heat transfer coefficient declines with heat flux increment. As a result, total thermal resistance $\left(R_{t h}\right)$ elevates with advancing heat flux (Figure 4$)$. In the literature, contradictory opinions are found about the influence of the heat flux on the heat transfer coefficient. Zhao et al., [28], Lee and Lee [29] reported that the two-phase heat transfer coefficient $\left(h_{t p}\right)$ is independent of the heat flux. On the other hand, Bertsch et al., [30] showed that $h_{t p}$ is strongly influenced by the heat flux.

From Figure 5 and Figure 6, it is observed that surface heat transfer coefficient, as well as $R_{t h}$ diminishes with the pumping power increment. Descending rate is high for lower pumping powers. 
Although the triangular fin micro-gap exhibits higher thermal resistance, the declining rate of $R_{\text {th }}$ with pumping power increment for the triangular fin micro-gap is quite higher than that of the rectangular fin heat sink. $60 \%$ reduction in total thermal resistance is achieved for triangular fin micro-gap, while for rectangular fin gap $R_{\text {th }}$ could be reduced only $53 \%$ for the total range of pumping power. After $\Omega$ $=2 \times 10^{-4} \mathrm{~W}$, the decrement rate drops off for both heat sinks. Hence, increment of pumping power is not always cost-effective. A similar trend was also reported by Hung and Yan [31] for the single-phase flow of water in a rectangular double-layer microchannel heat sink. Figure 7 and Figure 8 show that for the same heat flux and pumping power, the heat transfer rate decreases with the upsurging inlet void fraction.

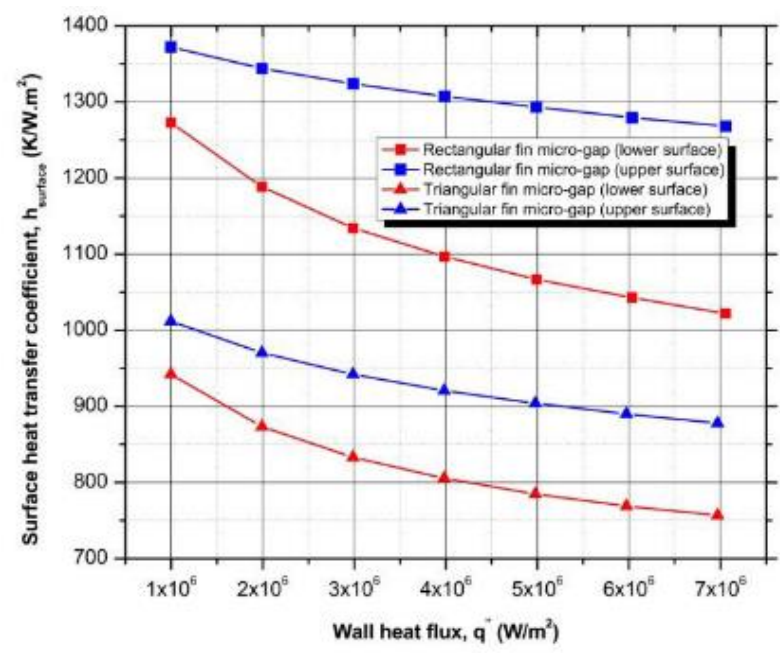

Fig. 3. Variation of the surface heat transfer coefficient with the wall heat flux $\left(\Omega=3 \times 10^{-3} \mathrm{~W}\right.$, $\alpha_{\text {in }}=0$ )

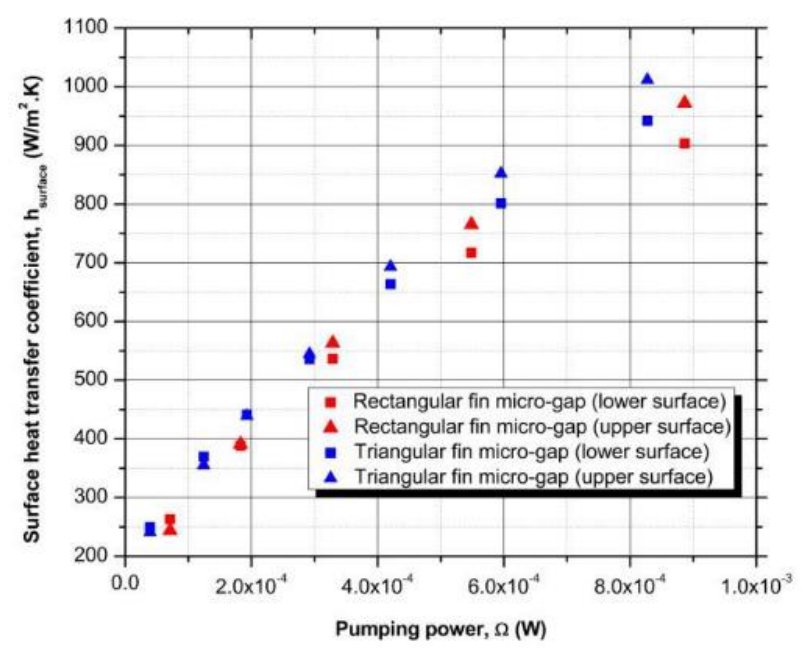

Fig. 5. Variation of the surface heat transfer coefficient with the pumping power $\left(q_{i n}=1 \times 10^{6}\right.$ $W m^{-2}, \alpha_{i n}=0$ )

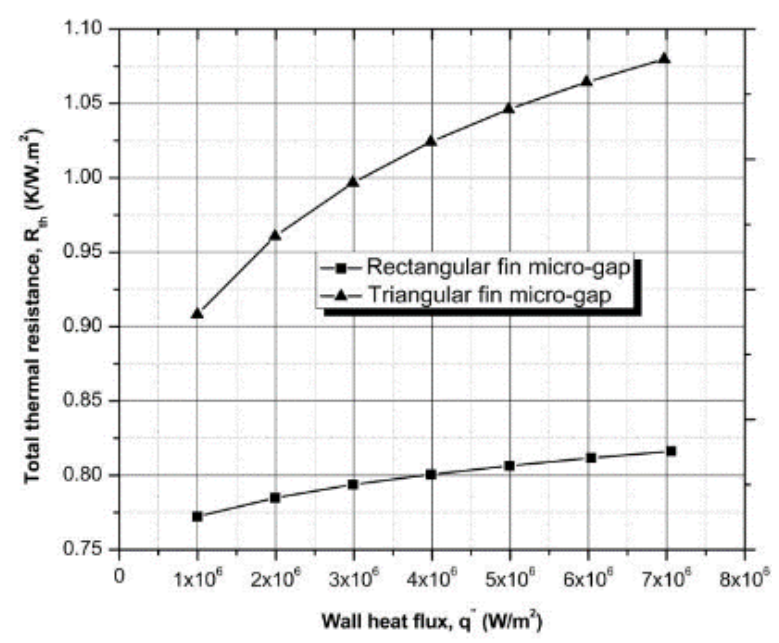

Fig. 4. Variation of the total thermal resistance with the wall heat flux $\left(\Omega=3 \times 10^{-3} \mathrm{~W}, \alpha_{i n}=0\right)$

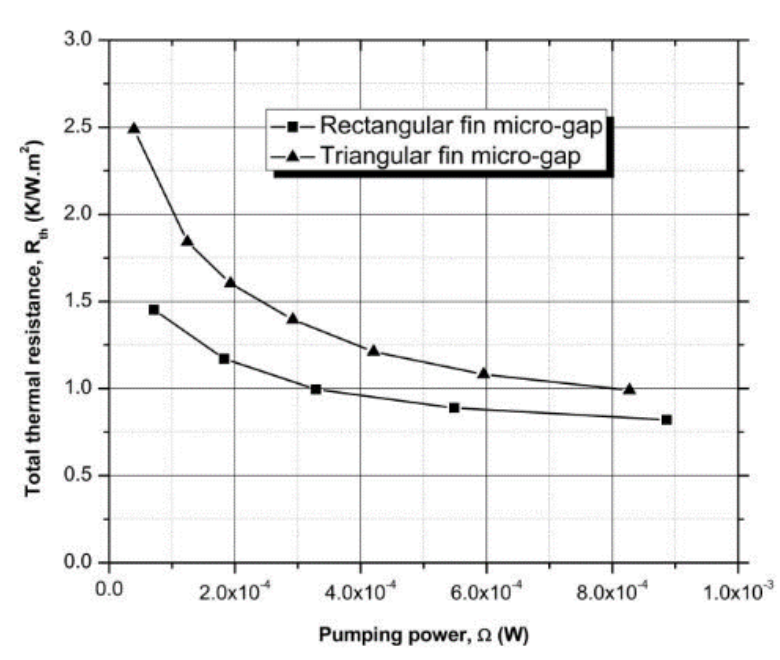

Fig. 6. Variation of the total thermal resistance with the pumping power $\left(q_{i n}=1 \times 10^{6} \mathrm{Wm}^{-2}, \alpha_{i n}=0\right)$ 


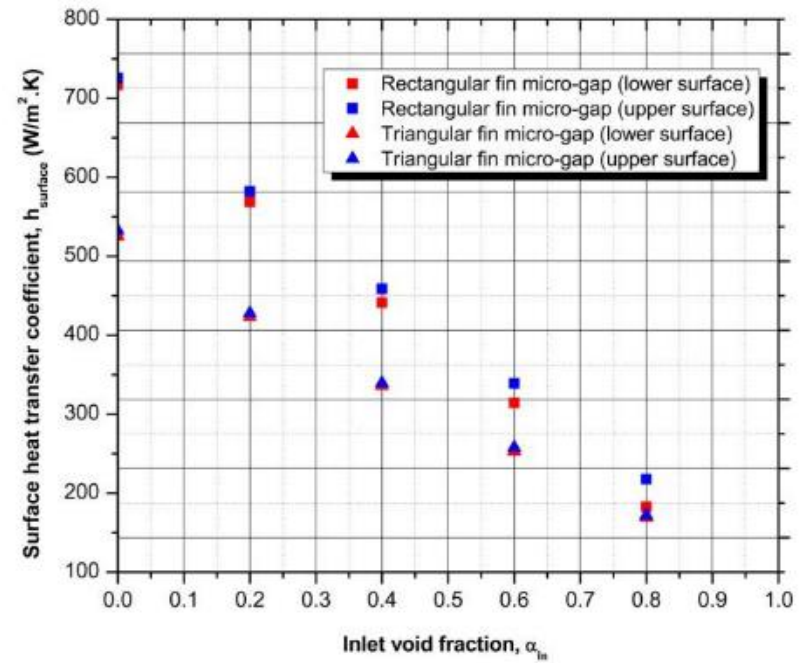

Fig. 7. Variation of the surface heat transfer coefficient with the inlet void fraction $\left(q_{i n}=1 \times 10^{6}\right.$ $W m^{-2}, \Omega=3 \times 10^{-3} \mathrm{~W}$ )

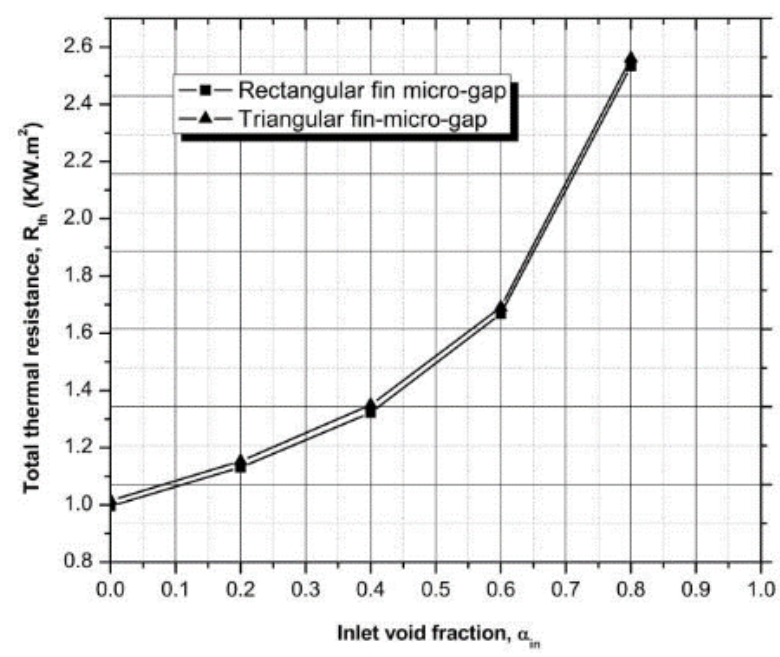

Fig. 8. Variation of the total thermal resistance with the inlet void fraction $\left(q_{i n}=1 \times 10^{6} \mathrm{Wm}^{-2}\right.$, $\left.\Omega=3 \times 10^{-3} \mathrm{~W}\right)$

\subsubsection{Pressure drop}

Pressure distribution in rectangular and triangular fin micro-gaps is illustrated in Figure 9 and Figure 10, respectively. It is seen that pressure decreases in the flow direction.

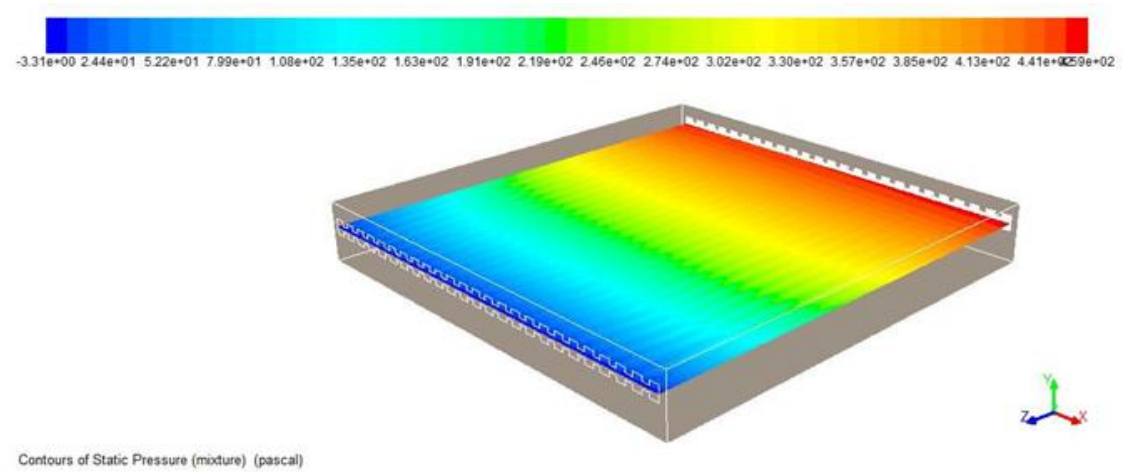

Fig. 9. Pressure distribution on $X-Z$ plane at $Y=2.5 \mathrm{~mm}$ in the rectangular fin micro-gap for $\Omega=2 \times 10^{-3} \mathrm{~W}, q_{\text {in }}=1 \times 10^{6} \mathrm{Wm}^{-2}, \alpha_{i n}=0$

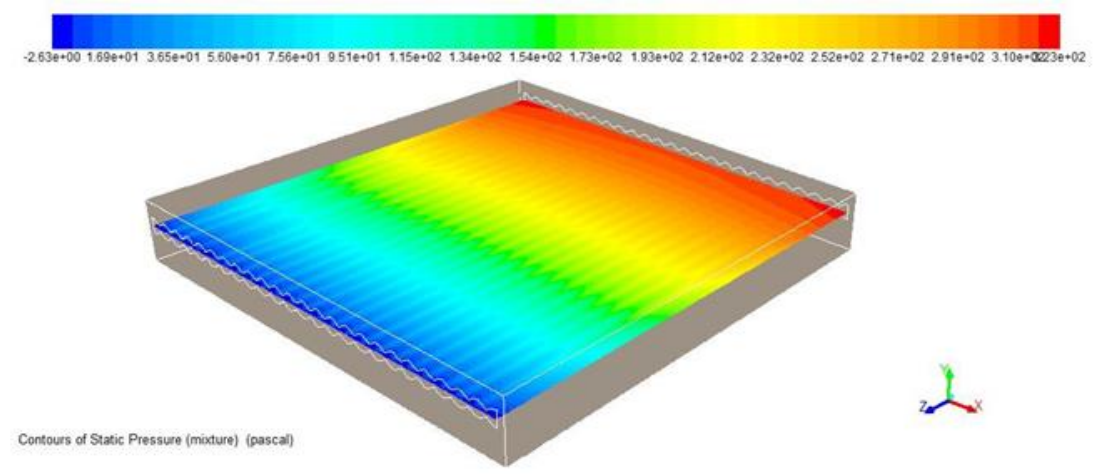

Fig. 10. Pressure distribution on $X-Z$ plane at $Y=2.5 \mathrm{~mm}$ in the triangular fin micro-gap for $\Omega=2 \times 10^{-3} \mathrm{~W}, q_{i n}=1 \times 10^{6} \mathrm{Wm}^{-2}, \alpha_{i n}=0$ 
From Figure 11 and Figure 12, it is apprehended that pressure drop ascents with improving heat flux and pumping power. However, a sharp decrement in the pressure drop is found for increasing inlet void fraction, shown in Figure 13. Vapor has lower viscosity compared to the liquid phase, which in turn reduces pressure drop.

Although the heat transfer performance of rectangular fin micro-gap is superior to the triangular fin heat sink, pressure drop in rectangular fin micro-gap is larger than triangular fin gap. As the crosssectional area of both heat sinks is the same $\left(2.18 \times 10^{-5} \mathrm{~m}^{2}\right)$, pressure drop variation occurs due to different surface areas. Pressure drop in rectangular fin micro-gap is higher due to larger surface area.

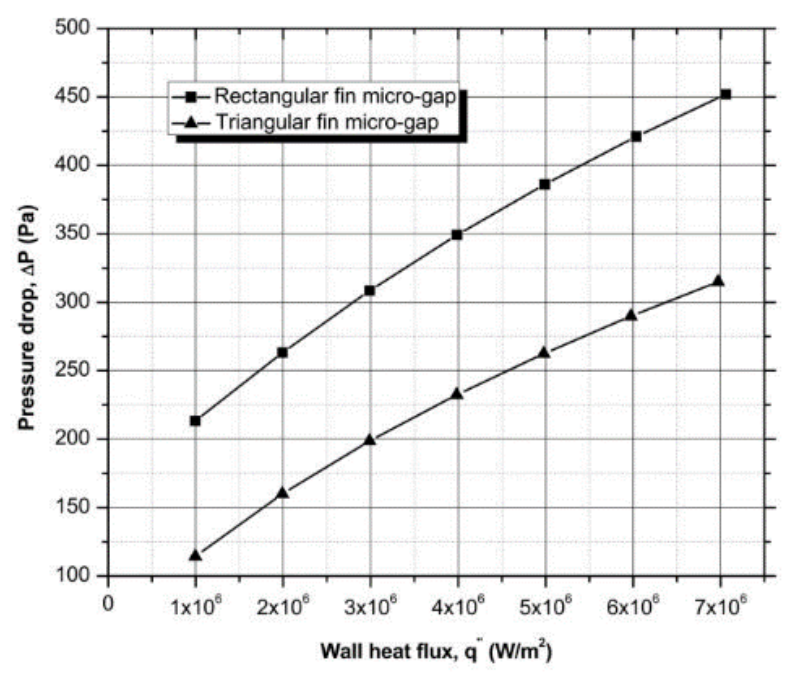

Fig. 11. Pressure drops in the rectangular and triangular fin micro-gaps for the wall heat flux variation $\left(\Omega=3 \times 10^{-3} \mathrm{~W}, \alpha_{i n}=0\right)$

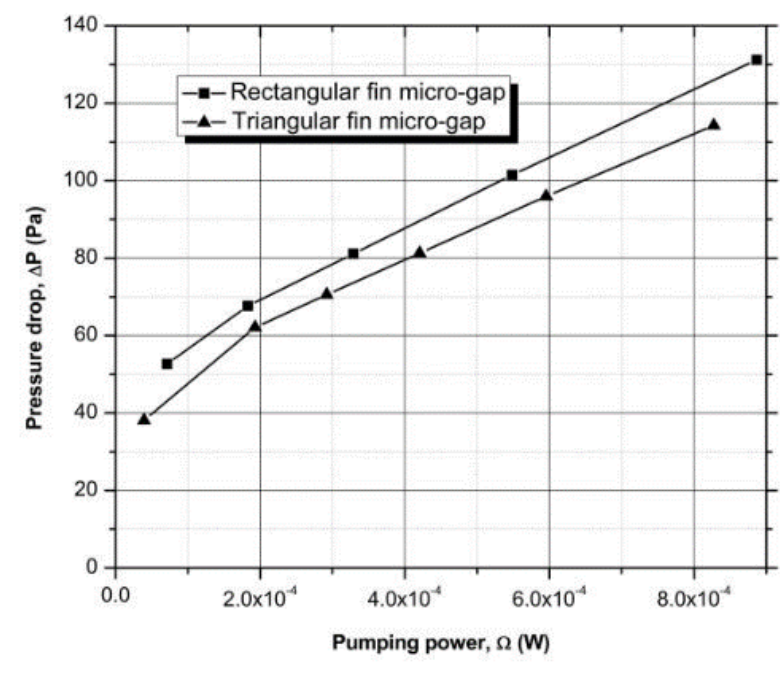

Fig. 12. Pressure drops in the rectangular and triangular fin micro-gaps for the pumping power variation $\left(q_{i n}=1 \times 10^{6} \mathrm{Wm}^{-2}, \alpha_{i n}=0\right)$

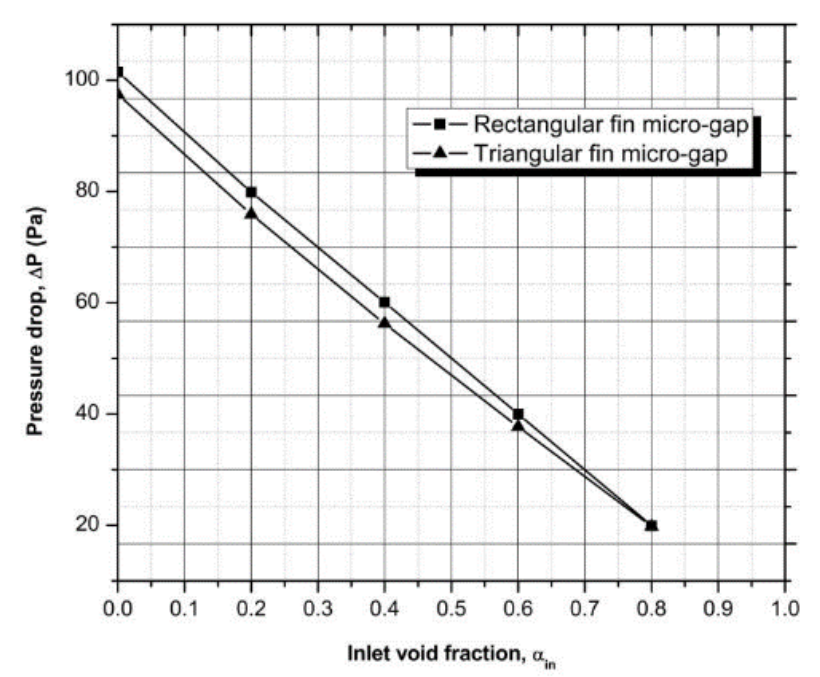

Fig. 13. Pressure drops in the rectangular and triangular fin micro-gaps for the inlet void fraction variation $\left(\Omega=5.5 \times 10^{-4} \mathrm{~W}, q_{i n}=1 \times 10^{6} \mathrm{Wm}^{-2}\right)$ 


\subsection{Optimization}

From numerical results, it is well understood that the total thermal resistance $\left(R_{t h}\right)$ of the system is a function of heat flux $(q)$, pumping power $(\Omega)$, and inlet void fraction $\left(\alpha_{i n}\right)$. Hence, $R_{\text {th }}$ can be minimized by optimizing these variables. Before that response surfaces should be plotted to describe the relationship between objective function and constraints. Design Expert 7.0.0 software has been used to plot the response surfaces and determine optimized values.

\subsubsection{Proposed optimized values}

From response surfaces, optimized operating conditions have been predicted to minimize total thermal resistance and pressure drop of the heat sink. The minimum value of $R_{t h}$ has been estimated from the range 0.785 to $2.96682 \mathrm{KW}^{-1} \mathrm{~m}^{-2}$ and $\Delta P$ from 9.9 to $451.89 \mathrm{~Pa}$. Many optimized input variables have been suggested by the Design Expert 7.0.0 software. Among all those values, the lowest predicted pressure drop is $57.8 \mathrm{~Pa}$ which is almost $87.2 \%$ lower than the highest $\Delta P$ value considered. For this pressure drop, $R_{t h}$ is reduced by $56.3 \%$ giving the estimated value of $1.298 \mathrm{KW}$ ${ }^{1} \mathrm{~m}^{-2}$. Estimated minimum $R_{\text {th }}$ and $\Delta P$ have been obtained for $\Omega=7.1208 \times 10^{-5} \mathrm{~W}, q^{\prime \prime}=1000002.07$ $\mathrm{Wm}^{-2}$ and $\alpha_{\text {in }}=0.03$. The contour plot for this selection is given in Figure 14 and Figure 15.

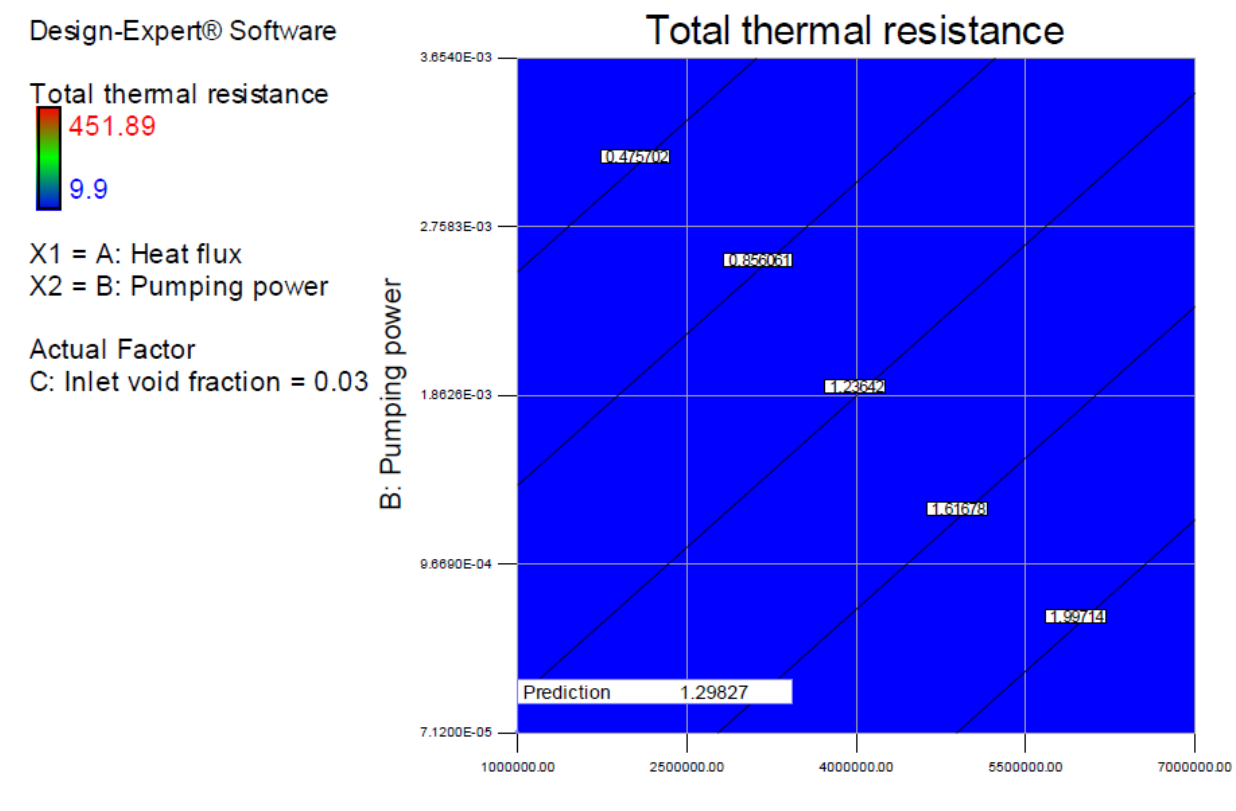

A: Heat flux

Fig. 14. Contour plot for lowest predicted total thermal resistance for optimized input variables 


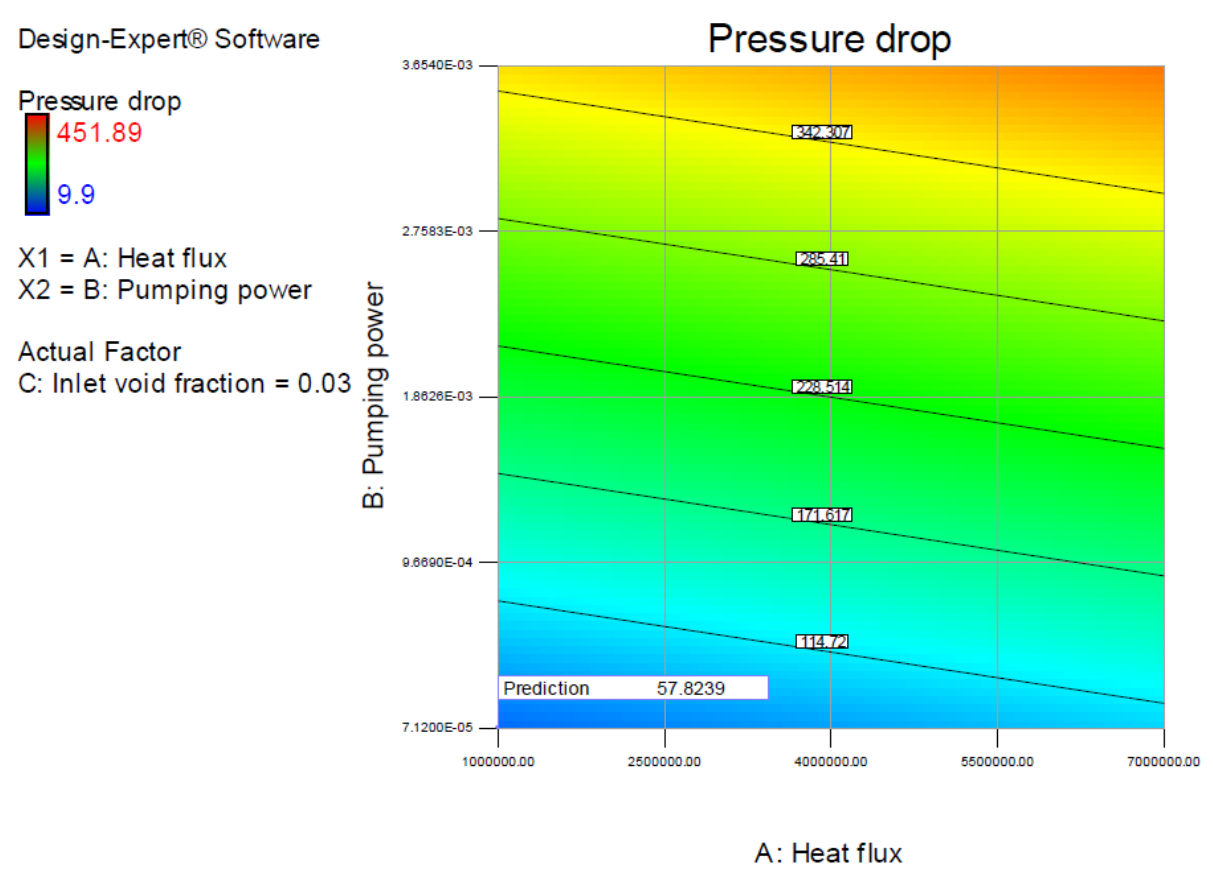

Fig. 15. Contour plot for lowest predicted pressure drop for optimized input variables

\section{Conclusions}

Following conclusions can be made from this research

i. Micro-gap with rectangular micro-fins shows less thermal resistance in comparison to triangular finned gaps.

ii. By increasing pumping power, thermal resistance $\left(R_{\text {th }}\right)$ has been reduced to $60 \%$ for triangular finned micro-gaps and 53\% for rectangular finned gaps. However, increasing pumping power is not always cost-effective as thermal resistance declines very slowly for larger pumping powers.

iii. A reduced value of total thermal resistance, $R_{\text {th }}\left(1.298 \mathrm{Km}^{2} / \mathrm{W}\right)$ and pressure drop, $\Delta P(57.8$ $\mathrm{Pa}$ ) for optimal operating conditions have been suggested. The predicted $\mathrm{R}_{\text {th }}$ is $56.3 \%$ and $\Delta \mathrm{P}$ is $87.2 \%$ lower than the highest values considered. The optimized operating conditions are $7.1202 \times 10^{-5} \mathrm{~W}$ pumping power, $1000002.07 \mathrm{Wm}^{-2}$ heat flux, and 0.03 inlet void fraction.

\section{Acknowledgment}

The support of Malaysian Ministry of Higher Education through International Islamic University Malaysia under the research grant FRGS19-126-0735 is gratefully acknowledged.

\section{References}

[1] Mishra, Umesh, and Jasprit Singh. Semiconductor device physics and design. Springer Science \& Business Media, 2007.

[2] Wang, Yuan, Khellil Sefiane, and Souad Harmand. "Flow boiling in high-aspect ratio mini-and micro-channels with FC-72 and ethanol: Experimental results and heat transfer correlation assessments." Experimental thermal and fluid science 36 (2012): 93-106. https://doi.org/10.1016/i.expthermflusci.2011.09.001

[3] Tuckerman, David B., and Roger Fabian W. Pease. "High-performance heat sinking for VLSI." IEEE Electron device letters 2, no. 5 (1981): 126-129. https://doi.org/10.1109/EDL.1981.25367

[4] Alam, Tamanna, Poh Seng Lee, Christopher R. Yap, and Liwen Jin. "Experimental investigation of microgap cooling technology for minimizing temperature gradient and mitigating hotspots in electronic devices." In 2011 IEEE 13 th 
Electronics Packaging Technology Conference, pp. 530-535. IEEE, 2011. https://doi.org/10.1109/EPTC.2011.6184478

[5] Alam, Tamanna, Poh Seng Lee, Christopher R. Yap, and Liwen Jin. "A comparative study of flow boiling heat transfer and pressure drop characteristics in microgap and microchannel heat sink and an evaluation of microgap heat sink for hotspot mitigation." International Journal of Heat and Mass Transfer 58, no. 1-2 (2013): 335-347. https://doi.org/10.1016/j.ijheatmasstransfer.2012.11.020

[6] Akbar, Ronald, A. S. Pamitran, and J. T. Oh. "Two-Phase Flow Boiling Heat Transfer Coefficient with R290 in Horizontal $3 \mathrm{~mm}$ Diameter Mini Channel." Journal of Advanced Research in Experimental Fluid Mechanics and Heat Transfer 3, no. 1 (2021): 1-8.

[7] Ahmed, Shugata, Ahmad Faris Ismail, Erwin Sulaeman, and Muhammad Hasibul Hasan. "A critical assessment on evaporative cooling performance of micro finned micro gap for high heat flux applications." ARPN Journal of Engineering and Applied Sciences 11, no. 1 (2016): 313-336.

[8] Ahmed, Shugata, Ahmad Faris Ismail, Erwin Sulaeman, and Muhammad Hasibul Hasan. "A Comparative Analysis of Flow Boiling in Micro-Gaps with Internal Micro-Fins of Rectangular and Triangular Profiles." International Journal of Applied Engineering Research 11, no. 4 (2016): 2364-2372.

[9] Ahmed, Shugata, Muhammad Hasibul Hasan, Ahmad Faris Ismail, and Erwin Sulaeman. "Effect of geometrical parameters on boiling heat transfer and pressure drop in micro finned micro gap." ARPN Journal of Engineering and Applied Sciences 11, no. 1 (2016): 297-302.

[10] Ahmed, Shugata, Ahmad Faris Ismail, Erwin Sulaeman, and Muhammad Hasibul Hasan. "Study on turbulent characteristics of flow boiling in a micro gap under the influence of surface roughness and micro fins." ARPN Journal of Engineering and Applied Sciences 11, no. 1 (2016): 410-414.

[11] Ahmed, S., E. Sulaeman, Ahmad Faris Ismail, and Muhammad Hasibul Hasan. "Two-Phase Fin-Induced Turbulent Cooling for Electronic Devices Using Heat Pump Associated Micro-Gap Heat Sink." International Journal of Engineering \& Technology, vol. (3.13), (2018): 113-122. https://doi.org/10.14419/ijet.v7i3.13.16336

[12] Ahmed, Shugata, Ahmad Faris Ismail, Erwin Sulaeman, and Muhammad Hasibul Hasan. "Experimental Correlation for Flow-boiling Heat Transfer in a Micro-gap Evaporator with Internal Micro-fins." Journal of Advanced Research in Fluid Mechanics and Thermal Sciences 54, no. 1 (2019): 1-8.

[13] Lin, Yuhao, Yang Luo, Evelyn N. Wang, Wei Li, and W. J. Minkowycz. "Enhancement of flow boiling heat transfer in microchannel using micro-fin and micro-cavity surfaces." International Journal of Heat and Mass Transfer 179 (2021): 121739. https://doi.org/10.1016/j.ijheatmasstransfer.2021.121739

[14] Yin, Liaofei, Peixue Jiang, Ruina Xu, and Haowei Hu. "Water flow boiling in a partially modified microgap with shortened micro pin fins." International Journal of Heat and Mass Transfer 155 (2020): 119819. https://doi.org/10.1016/j.ijheatmasstransfer.2020.119819

[15] Li, Y. F., G. D. Xia, D. D. Ma, J. L. Yang, and W. Li. "Experimental investigation of flow boiling characteristics in microchannel with triangular cavities and rectangular fins." International Journal of Heat and Mass Transfer 148 (2020): 119036. https://doi.org/10.1016/j.ijheatmasstransfer.2019.119036

[16] Liao, Wun-Rong, Liang-Han Chien, Mohammad Ghalambaz, and Wei-Mon Yan. "Experimental study of boiling heat transfer in a microchannel with nucleated-shape columnar micro-pin-fins." International Communications in Heat and Mass Transfer 108 (2019): 104277. https://doi.org/10.1016/j.icheatmasstransfer.2019.104277

[17] Khan, Waqar Ahmed, M. M. Yovanovich, and J. R. Culham. "Optimization of microchannel heat sinks using entropy generation minimization method." In Twenty-Second Annual IEEE Semiconductor Thermal Measurement And Management Symposium, pp. 78-86. IEEE, 2006.

[18] Chen, Chien-Hsin. "Forced convection heat transfer in microchannel heat sinks." International Journal of Heat and Mass Transfer 50, no. 11-12 (2007): 2182-2189. https://doi.org/10.1016/j.ijheatmasstransfer.2006.11.001

[19] Asgari, Omid, and Mohammad Hassan Saidi. "Approximate method of determining the optimum cross section of microhannel heat sink." Journal of mechanical science and technology 23, no. 12 (2009): 3448-3458. https://doi.org/10.1007/s12206-009-1018-8

[20] Kim, Dong-Kwon, Jaehoon Jung, and Sung Jin Kim. "Thermal optimization of plate-fin heat sinks with variable fin thickness." International Journal of Heat and Mass Transfer 53, no. 25-26 (2010): 5988-5995. https://doi.org/10.1016/j.ijheatmasstransfer.2010.07.052

[21] Baodong, Shao, Wang Lifeng, Li Jianyun, and Cheng Heming. "Multi-objective optimization design of a microchannel heat sink using adaptive genetic algorithm." International Journal of Numerical Methods for Heat \& Fluid Flow (2011). https://doi.org/10.1108/09615531111108512

[22] Hung, Tu-Chieh, Wei-Mon Yan, Xiao-Dong Wang, and Yu-Xian Huang. "Optimal design of geometric parameters of double-layered microchannel heat sinks." International Journal of Heat and Mass Transfer 55, no. 11-12 (2012): 3262-3272. https://doi.org/10.1016/j.ijheatmasstransfer.2012.02.059 
[23] Adham, Ahmed Mohammed, Normah Mohd-Ghazali, and Robiah Ahmad. "Optimization of an ammonia-cooled rectangular microchannel heat sink using multi-objective non-dominated sorting genetic algorithm (NSGA2)." Heat and Mass transfer 48, no. 10 (2012): 1723-1733. https://doi.org/10.1007/s00231-012-1016-8

[24] Hirt, Cyril W., and Billy D. Nichols. "Volume of fluid (VOF) method for the dynamics of free boundaries." Journal of computational physics 39, no. 1 (1981): 201-225. https://doi.org/10.1016/0021-9991(81)90145-5

[25] Orszag, S. A., V. Yakhot, and W. S. Flanney. "Renormalization group modeling and turbulence, in international conference on near-wall turbulent flows." In Proceedings of the International Symposium on Mathematical Modeling of Turbulent Flows. Tokyo, Japan. 1995.

[26] Touaibi, Rabah, and Hasan Koten. "Energy Analysis of Vapor Compression Refrigeration Cycle Using a New Generation Refrigerants with Low Global Warming Potential." Journal of Advanced Research in Fluid Mechanics and Thermal Sciences 87, no. 2 (2021): 106-117. https://doi.org/10.37934/arfmts.87.2.106117

[27] Gunnasegaran, Prem, H. A. Mohammed, N. H. Shuaib, and Rahman Saidur. "The effect of geometrical parameters on heat transfer characteristics of microchannels heat sink with different shapes." International communications in heat and mass transfer 37, no. 8 (2010): 1078-1086. https://doi.org/10.1016/j.icheatmasstransfer.2010.06.014

[28] Zhao, Yuan, Majid Molki, Michael M. Ohadi, and S. V. Dessiatoun. Flow boiling of CO in microchannels. Univ. of Maryland, College Park, MD (US), 2000.

[29] Lee, Han Ju, and Sang Yong Lee. "Heat transfer correlation for boiling flows in small rectangular horizontal channels with low aspect ratios." International Journal of Multiphase Flow 27, no. 12 (2001): $2043-2062$. https://doi.org/10.1016/S0301-9322(01)00054-4

[30] Bertsch, Stefan S., Eckhard A. Groll, and Suresh V. Garimella. "Effects of heat flux, mass flux, vapor quality, and saturation temperature on flow boiling heat transfer in microchannels." International Journal of Multiphase Flow 35, no. 2 (2009): 142-154. https://doi.org/10.1016/j.ijmultiphaseflow.2008.10.004

[31] Hung, Tu-Chieh, and Wei-Mon Yan. "Enhancement of thermal performance in double-layered microchannel heat sink with nanofluids." International Journal of Heat and Mass Transfer 55, no. 11-12 (2012): 3225-3238. https://doi.org/10.1016/j.ijheatmasstransfer.2012.02.057 